\title{
Live attenuated measles virus vaccine induces apoptosis and promotes tumor regression in lung cancer
}

\author{
DANHUA ZHAO ${ }^{1}$, PING CHEN $^{2}$, HUIQIANG YANG $^{2}$, YONGLIN WU $^{2}$, XIANWU ZENG $^{2}$, \\ YU ZHAO $^{2}$, YANJUN WEN ${ }^{1}$, XIA ZHAO $^{1}$, XIAOLIN LIU $^{3}$, YUQUAN WEI $^{1}$ and YUHUA LI ${ }^{1,4}$ \\ ${ }^{1}$ State Key Laboratory of Biotherapy and Cancer Center, West China Hospital, West China Medical School, \\ Sichuan University, Chengdu 610041; ${ }^{2}$ Chengdu Institute of Biological Products, Chengdu 610023; \\ ${ }^{3}$ Tiantan Company of Biological Products, Beijing 100024; ${ }^{4}$ Department of Arboviral Vaccines and \\ Key Laboratory of the Ministry of Health for Research on Quality and Standardization of Biotech Products, \\ National Institute for Food and Drug Control, Beijing 100050, P.R. China
}

Received September 28, 2012; Accepted October 22, 2012

DOI: 10.3892/or.2012.2109

\begin{abstract}
Although the treatment of lung carcinoma has improved, at least $65 \%$ of patients with this tumor succumb to progressive disease. Measles virus oncolytic therapy has been reported to be effective in reducing tumor burden in immunocompetent or nude mice; however, its potential to reduce tumor burden in lung carcinoma remains to be determined. Herein, we report the potent antitumor effects of a live attenuated measles vaccine virus Hu-191 strain (MV) against lung carcinoma. Immunocompetent C57BL/6 mice bearing Lewis lung carcinoma (LLC) cells were treated with MV $\left(1 \times 10^{4}\right.$ to $1 \times 10^{6} \mathrm{CCID}_{50} / \mathrm{ml}$ ) once every other day for 10 days. Our results showed that treatment with MV effectively suppressed tumor growth and significantly prolonged the survival time of tumorbearing animals. Histological examination revealed that the antitumor effects of MV therapy may result from increased induction of apoptosis, tumor necrosis and elevated lymphocyte infiltration. Our data suggest that MV, one of the widely used vaccines in China, has the ability to inhibit the growth of mouse lung carcinoma and may prove useful in the further exploration of the application of this approach in the treatment of human advanced lung cancer.
\end{abstract}

\section{Introduction}

Lung cancer is the leading cause of cancer-related morbidity and mortality, resulting in more than 1.1 million deaths worldwide $(1,2)$. Approximately $75-80 \%$ of lung cancer cases are

Correspondence to: Dr Yuhua Li, Department of Arboviral Vaccines and Key Laboratory of the Ministry of Health for Research on Quality and Standardization of Biotech Products, National Institute for Food and Drug Control, No. 2 Tiantan Xili, Dongcheng District, Beijing 100050, P.R. China

E-mail: liyuhua@hotmail.com

Key words: live attenuated measles virus vaccine, apoptosis, oncolytic therapy non-small cell lung cancer (NSCLC), and 65\% of these patients have advanced-stage disease at diagnosis (3). Despite the aggressive approaches achieved in the therapy of lung cancer in the past decades, the prognosis of NSCLC remains poor, with 5-year survival rates of 5-14\%, even when patients are treated with surgery, radiotherapy and/or chemotherapy (4-6). Therefore, efforts to develop new and less toxic therapeutic approaches for the treatment of lung cancer are ongoing.

Measles virus, one member of the Paramyxoviridae family, is a negative strand RNA virus. The typical cytopathic effect of Measles virus is the formation of multinuclear cell aggregates (syncytia), which result from the fusion of infected cells. The wild-type virus enters cells exclusively via the SLAM receptor, one of the surface hemagglutinin $(\mathrm{H})$ glycoproteins predominantly found on activated B and T lymphocytes (9-11). In contrast, the attenuated measles vaccine virus Edmonston strain preferentially infects cells with the CD46 receptor $(12,13)$, which is frequently overexpressed in tumor cells (14). In addition, measles vaccine strains are attenuated and have an excellent safety record with several hundred millions of vaccine doses having been safely administered in over 40 years of use. These preferences enable the attenuated measles vaccine virus to be tumor-selective and result in minimal cytopathic effects on normal tissue.

Previous studies have shown that live attenuated measles virus Edmonston $\mathrm{B}$ strain has potent and specific oncolytic activity against a variety of human tumor types, including lymphoma, multiple myeloma, epithelial ovarian cancer and glioma (15-20). Thus, the present study was designed to evaluate the therapeutic effects of live attenuated measles vaccine virus Hu-191 strain (MV) for the treatment of lung carcinoma. This study demonstrated that the oncolytic therapy exhibits powerful antitumor effects against murine lung carcinoma and provides potential implications for the treatment of human lung cancer.

\section{Materials and methods}

Cell lines. LLC, A549 and HEK 293T cells were purchased from the American Type Culture Collection (Rockville, 
MD, USA). They were maintained in monolayer cultures in DMEM, supplemented with $10 \%$ heat-inactivated fetal bovine serum (FBS), at $37^{\circ} \mathrm{C}$ in a humidified atmosphere containing $5 \% \mathrm{CO}_{2}$. Live attenuated measles vaccine virus Hu-191 strain was obtained from Chengdu Company of Biological Products.

MTT colorimetric assay. Survival of cells after treatment was quantified using 3-(4,5-dimethylthiazol-2-yl)-2,5-diphenyl tetrazolium bromide (MTT; Sigma, St. Louis, MO, USA) colorimetric assay (21). Briefly, LLC and A549 cells were seeded in 96 -well plates $\left(1 \times 10^{4} / \mathrm{ml}\right)$. They were treated with $\mathrm{MV}$ or PBS. Each well was supplemented with $20 \mu 1$ of $5 \mathrm{mg} / \mathrm{ml}$ MTT in complete media and incubated at $37^{\circ} \mathrm{C}$ for $4 \mathrm{~h}$. The medium and MTT solution were then removed, and $150 \mu \mathrm{l}$ of dimethyl sulfoxide (DMSO) was added to each well. 293T cells were also treated as a non-transformed cell control. Absorbance was read at $490 \mathrm{~nm}$ using a microplate reader. Data were the average of 6 wells, and the experiment was repeated 3 times with similar results. Medium only-treated cells served as the indicator of $100 \%$ cell viability.

Assessment of apoptosis in vitro. Cell apoptosis was analyzed by DNA ladder and flow cytometry (Annexin V-FITC Apoptosis Detection kit; Sigma). The pattern of DNA cleavage was analyzed by agarose gel electrophoresis as described (22). Briefly, cells $\left(1 \times 10^{6}\right)$ were lysed with $0.1 \mathrm{ml}$ lysis buffer containing $50 \mathrm{mM}$ Tris- $\mathrm{HCl}(\mathrm{pH} \mathrm{8.0)}, 1 \%$ Nonidet $\mathrm{P}-40$ and $20 \mathrm{mM}$ EDTA, followed by the addition of RNase A (Sigma) at a final concentration of $10 \mu \mathrm{g} / \mu \mathrm{l}$ and incubated at $37^{\circ} \mathrm{C}$ for $1 \mathrm{~h}$. Cells were then treated with $2.5 \mu \mathrm{g} / \mu \mathrm{l}$ proteinase $\mathrm{K}$ overnight at $37^{\circ} \mathrm{C}$. Samples $(10 \mu \mathrm{l})$ in each lane were subjected to electrophoresis on $1.5 \%$ agarose at $50 \mathrm{~V}$ for $3 \mathrm{~h}$. DNA was stained with ethidium bromide.

Cells were collected and resuspended in $1 \mathrm{X}$ binding buffer at a concentration of $1 \times 10^{6}$ cells $/ \mathrm{ml}$. Annexin V-FITC conjugate $(5 \mu \mathrm{l})$ and $10 \mu \mathrm{l}$ of propidium iodide solution (22-24) were added to each cell suspension. After $10 \mathrm{~min}$ of incubation at room temperature, cells were analyzed by flow cytometry. Cells undergoing early apoptosis were stained with the Annexin V-FITC conjugate alone. Live cells showed no staining by either the propidium iodide solution or Annexin V-FITC conjugate. Necrotic cells were stained by both the propidium iodide solution and Annexin V-FITC conjugate.

Murine tumor model and treatment. Lewis lung carcinoma (LLC) cells $\left(1 \times 10^{6}\right.$ to $1 \times 10^{7}$ cells) were inoculated subcutaneously in the right flanks of C57BL/6 mice 6-8 weeks of age. To explore the therapeutic efficacy of MV, we treated the mice on day 15 after the implantation of tumor cells, when the size of tumors reached $\sim 30 \mathrm{~mm}^{3}$. The mice were randomly divided into 4 groups ( 5 male and 5 female mice/group). Approximately $1 \times 10^{6}, 1 \times 10^{5}, 1 \times 10^{4} \mathrm{CCID}_{50} / \mathrm{ml}$ of MV or PBS were injected into the tumor every other day for 5 times. Tumor volume was determined by the following formula: Tumor volume $\left(\mathrm{mm}^{3}\right)$ $=\pi / 6 \times$ length $(\mathrm{mm}) \times$ width $(\mathrm{mm}) \mathrm{x}$ width $(\mathrm{mm})$. All of the studies involving mice were performed in accordance with institutional guidelines concerning animal use and care. On day 4 after the completion of treatment as described above, the mice were sacrificed by cervical dislocation. Mouse tissues of interest were excised and fixed in $10 \%$ neutral buffered formalin solution or frozen at $80^{\circ} \mathrm{C}(25)$.

Histological analysis. For the observations of potential side effects in the treated mice, the tissues from each group were embedded in paraffin. Sections $(3-5 \mu \mathrm{m})$ were stained with hematoxylin and eosin (H\&E) (26). Immunostaining for MV was performed as previously described (27). Briefly, paraffin-embedded tissue sections from the treated mice were incubated with a polyclonal rabbit antibody against MV at a 1:300 dilution at $4^{\circ} \mathrm{C}$ overnight. Following washes, the secondary antibody, biotinylated goat anti-rabbit antibody at a 1:100 dilution (Dako, Carpinteria, CA), was added. Sections were then stained with streptavidin biotin reagents (Dako LSAB kit; peroxidase). Immunofluorescence staining was used to determine the infiltration of cytotoxic T lymphocytes (CTLs) in the tumor tissue. The frozen sections were blocked (10\% FBS, 3\% BSA) for 30 min before staining with the antiCD4 antibody (ab51312; Abcam, USA) and anti-CD8 antibody (ab22378; Abcam). Fluorescence was visualized, and images were captured with fluorescence microscopy.

Quantitative assessment of apoptosis. Tumor species were prepared as described above. The presence of apoptotic cells within the tumor sections was determined using the In Situ Cell Death Detection kit (Fluorescein; Roche), following the manufacturer's instructions. It is based on the enzymatic addition of digoxigenin nucleotide to the nicked DNA by terminal deoxynucleotidyl transferase (28). In the tissue sections, four equal-sized fields were randomly chosen and analyzed. As a proliferation marker, Ki67 is required for maintaining cell proliferation. Immunohistochemical analysis with the anti-Ki67 antibody (ab16667; Abcam) was used to measure proliferation in the tumor tissue.

Evaluation of potential adverse effects. To evaluate the potential side effects or toxicity on mice during the treatment, gross measures such as weight loss, ruffling of fur, lifespan, behavior and feeding were investigated. Tissues from the heart, liver, spleen, lung, kidney and brain were fixed in $10 \%$ neutral buffered formalin solution, embedded in paraffin, and stained with H\&E.

Data analysis and statistics. In order for the comparison of individual time points, data were assayed by variance (ANOVA) and an unpaired Student's t-test (29). Survival analysis was computed by the Kaplan-Meier method and compared by the log-rank test (30). A P-value of $<0.05$ was considered to indicate a statistically significant difference.

\section{Results}

In vitro induction of apoptosis of lung cancer cell lines with $M V$ treatment. To study the ability of MV to augment the induction of apoptosis of cells, we treated the various cell lines with MV. A549, LLC and 293T cells were seeded in cell culture flasks separately in appropriate culture. As shown in Fig. 1A, MV increased the cytopathic effect on both the A549 and LLC cell lines compared with the control group. Cell viability was also determined by MTT assay. As shown 
in Fig. 1B, the treatment of MV reduced the A549 and LLC cell viability by 60 and $62 \%$, respectively, whereas the treatment with MV reduced 293T cell viability by $31 \%$. These results indicated that the treatment of MV resulted in additive cytotoxicity to A549 and LLC lung cancer cells. However, the treatment showed less effect on $293 \mathrm{~T}$ cell viability when compared with the nontransformed cell control.

In the next set of experiments, we aimed to determine increased cell apoptosis induced by MV. Flow cytometry was used to estimate the number of apoptotic cells. As shown in Fig. 2A, treatment with MV increased the number of apoptotic cells compared with the control groups. Furthermore, agarose gel electrophoresis of MV demonstrated a ladder-like pattern of DNA fragments consisting of multiples of $\sim 150-200 \mathrm{bp}$, consistent with internucleosomal DNA fragmentation (Fig. 2B).

In vivo inhibition of growth of established lung carcinoma in mice. To determine the antitumor activity of $\mathrm{MV}$ in vivo, immunocompetent C57BL/6 mice bearing LLC Lewis lung carcinoma were treated with various amounts of $\mathrm{MV}$ or PBS. Our findings showed that both $10^{4} \mathrm{CCID}_{50} / \mathrm{ml} \mathrm{MV}$ and $10^{5} \mathrm{CCID}_{50} / \mathrm{ml} \mathrm{MV}$ resulted in effective suppression of tumor growth. However, the treatment of $10^{6} \mathrm{CCID}_{50} / \mathrm{ml} \mathrm{MV} \mathrm{had} \mathrm{a}$ superior antitumor effect, resulting in $>50 \%$ inhibition in tumor volume compared with the PBS group. No significant difference in tumor volumes was observed between the $10^{4} \mathrm{CCID}_{50} / \mathrm{ml} \mathrm{MV}$ and $10^{5} \mathrm{CCID}_{50} / \mathrm{ml} \mathrm{MV}$ groups (Fig. 3A). Moreover, a significant increase in the survival rate was observed in the $10^{6} \mathrm{CCID}_{50} /$ ml MV-treated mice ( $\mathrm{P}<0.05$, by log-rank test; Fig. 3B). In addition, $10^{6} \mathrm{CCID}_{50} / \mathrm{ml} \mathrm{MV}$ therapy effectively prolonged the lifespan of the tumor-bearing animals.

In vivo induction of apoptosis following MV treatment. Having confirmed the antitumor activity in LLC Lewis lung carcinoma models, we examined apoptosis-related molecular markers in tumor sections. An apoptosis detection kit (TUNEL) was used to detect early DNA fragmentation associated with apoptosis. Apoptotic cells were noted within the
A
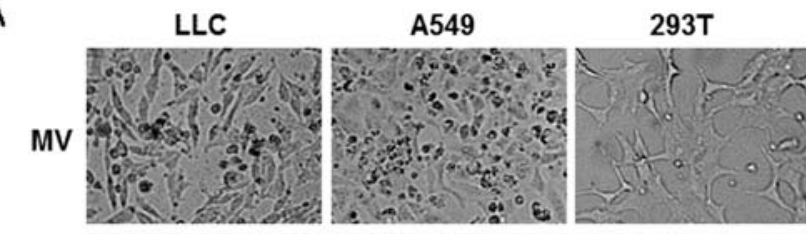

PBS
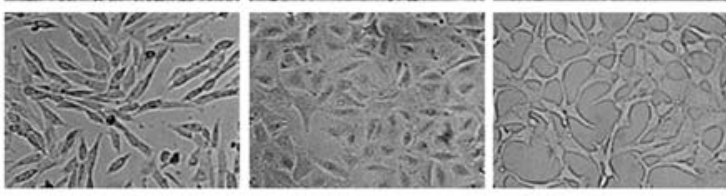

B

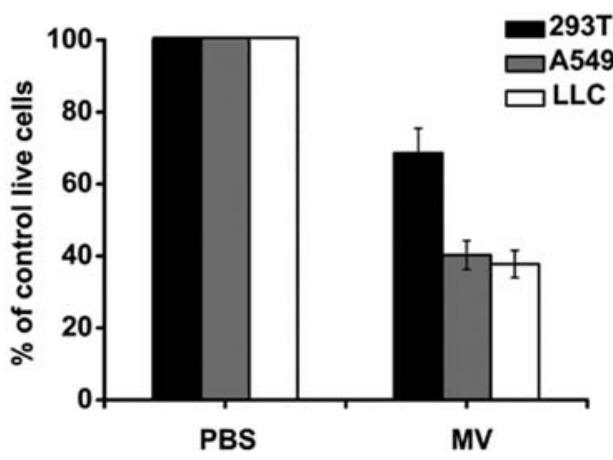

Figure 1. Induction of cytotoxicity in lung cancer cell lines in vitro following MV treatment. LLC, A549 and 293T cells treated with PBS were used as controls. (A) Phase-contrast micrographs of monolayers were recorded. Cell viability was also determined by MTT assay. (B) Results of the MTT assays are shown as mean $\pm \mathrm{SD}$ of 6 wells and triplicate experiments. In each experiment, the media-only treatment indicates $100 \%$ cell viability.

tumors treated with $10^{6} \mathrm{CCID}_{50} / \mathrm{ml} \mathrm{MV}$, compared with the treatment with $10^{5} \mathrm{CCID}_{50} / \mathrm{ml} \mathrm{MV}$ or $10^{4} \mathrm{CCID}_{50} / \mathrm{ml} \mathrm{MV} \mathrm{or}$ PBS groups (Fig. 4A). We also tested the proliferation index of tumor tissues. Immunohistochemical analysis with the anti-Ki67 antibody, which is used to measure proliferation in tumor tissues, showed less proliferative cells within the tumors treated with $10^{6} \mathrm{CCID}_{50} / \mathrm{ml} \mathrm{MV}$, compared with the other three groups (Fig. 4B).
A

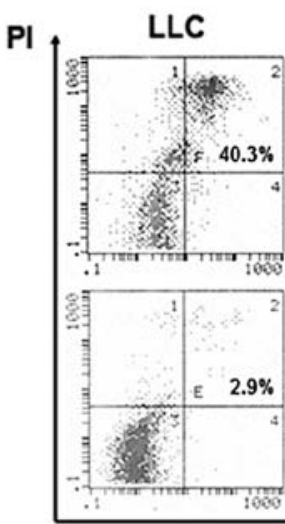

A549
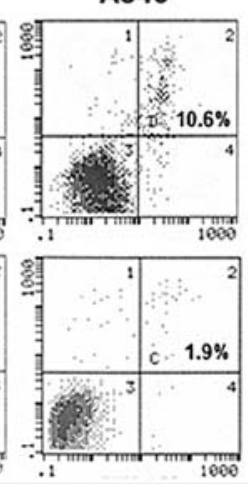

293T

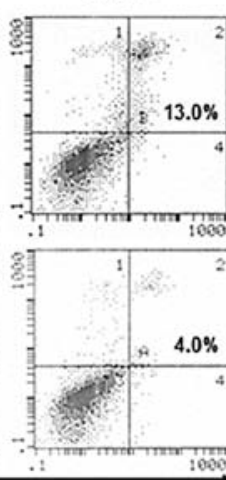

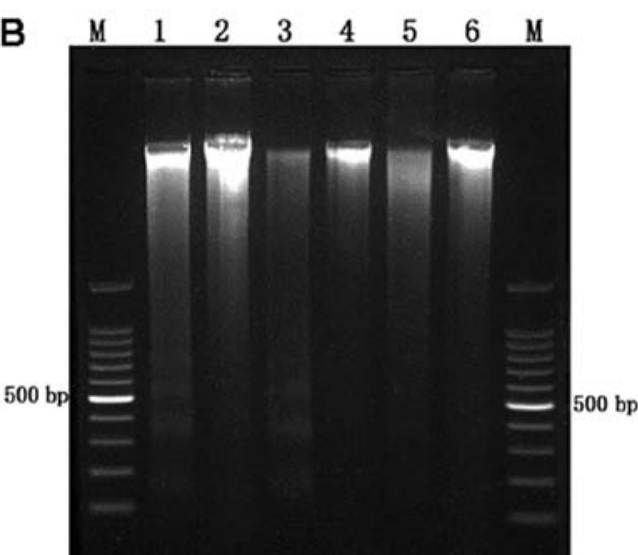

Annexin V

Figure 2. Induction of apoptosis following treatment with MV in vitro. (A) Fluorescence analysis of apoptosis. Cells were analyzed by FACS after staining with Annexin V and propidium iodide (PI). Percentages of positive cells within a quadrant are indicated. (B) Agarose gel electrophoretic patterns of DNA. M, DNA marker; lane 1, LLC cells treated with MV; lane 2, LLC treated with PBS; lane 3, A549 cells treated with MV; lane 4, A549 treated with PBS; lane 5, 293 T cells treated with MV; lane 6; 293T treated with PBS. 
A

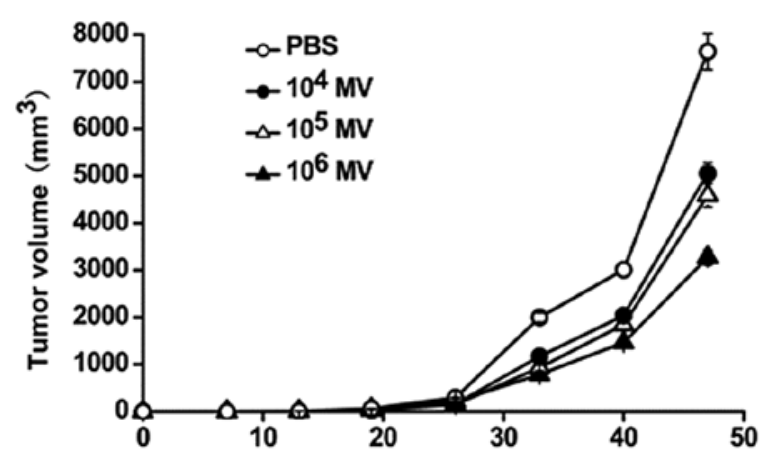

B

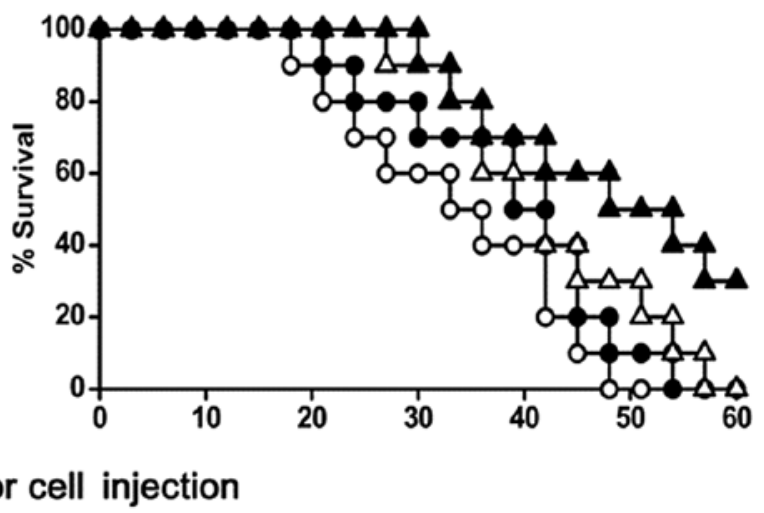

Figure 3. Tumor suppression and survival advantage in mice. Tumor-bearing mice (15 days after tumor cell implantation) were injected intratumorally with a $0.1 \mathrm{ml}$ total volume of $1 \times 10^{6}, 1 \times 10^{5}, 1 \times 10^{4} \mathrm{CCID}_{50} / \mathrm{ml}$ of $\mathrm{MV}$ or PBS, respectively, every other day for 5 times. It was evident that, compared with control groups, $10^{6} \mathrm{CCID}_{50} / \mathrm{ml} \mathrm{MV}$-treated mice showed a significant tumor volume decrease and survival time prolongation in the LLC cell model (P<0.05).

MV antigen-positive tumor cells were found within the tumors treated with MV, which confirmed that MV was capable of replicating in tumors. Virus antigen was detectable within either apoptotic cells or the intact tumor cells (Fig. 5A).

Histological analysis of intratumoral T-cell infiltration. To determine whether the therapy improved the infiltration of CD4 and CD8 lymphocytes into the tumors, anti-CD4 and anti-CD8 monoclonal antibodies were used in the immunofluorescence staining. The results showed that $10^{6} \mathrm{CCID}_{50} / \mathrm{ml}$ $\mathrm{MV}$ or $10^{5} \mathrm{CCID}_{50} / \mathrm{ml} \mathrm{MV}$ significantly increased the infiltration of both $\mathrm{CD}^{+}$and $\mathrm{CD} 8^{+}$lymphocytes (Fig. 6).

Histological examination of tumor sections by $\mathrm{H} \& \mathrm{E}$ staining showed that PBS-treated group tumor cells had well-defined cell borders and hyperchromatic nuclei. The cytoplasm of these cells was vesicular and eosinophilic, with evidence of mitosis. In contrast, tumors from mice treated with MV showed extensive necrosis, characterized by loss of nuclear staining, increased cytoplasmic eosinophilia, and loss of cellular detail and cell borders (Fig. 5B).

Observation of potential toxicity. To evaluate the possible adverse effects of the treatments, the body weights of the mice were monitored every 7 days throughout the entire experiment and these values were considered as a variable for the evaluation of systemic well-being or cachexia. No significant differences in weights were found among the four groups. No adverse consequences in other gross measures such as ruffling of fur, behavior, feeding, or toxic death were observed in the $10^{6} \mathrm{CCID}_{50} / \mathrm{ml} \mathrm{MV}$-treated group. In the histopathological examination of the tissues, there was also no significant differences. Therefore, we confirmed that MV treatment is safe and effective.

\section{Discussion}

The beneficial effects of viral infections on cancer patients have been known for decades. Numerous viruses, such as adenovirus, vesicular stomatitis virus and measles virus, are currently considered as potential cancer therapeutics $(31,32)$.
Among them, measles virus was successfully used to treat multiple tumors, including myeloma, ovarian cancer and glioma after either intratumoral, intraperitoneal, or intravenous administration $(7,19,20)$. Lung carcinoma is an aggressive tumor highly resistant to current therapeutic approaches, such as chemotherapy or radiotherapy (8). These studies suggest a substantial antineoplastic potential for measles virus. The present studies were designed to test the therapeutic efficacy of MV in murine lung carcinoma.

The data in the present study showed that MV oncolytic therapy not only specifically and significantly reduced the growth of highly tumorigenic and poorly immunogenic LLC cells but also effectively improved the survival of tumor-bearing animals. Although the exact mechanism remains to be determined, the antitumor efficacy of MV in vivo may in part result from the increased induction of apoptosis following treatment. This suggestion is supported by the present findings. In vitro treatment with MV significantly reduced the viability (Fig. 1) and increased the apoptosis of tumor cells compared with PBS treatment (Fig. 2). In addition, more apparent apoptotic cells were found in the tumors treated with MV compared with the PBS-treated group. The mechanism by which MV leads to tumor cell apoptosis may be related to virus replication. This feature of viral replication provides continuous amplification of the input dose which continues until being stopped by the immune response or a lack of susceptible cells.

Breaking of immune tolerance against self-tumor antigen and induction of auto-immunity against tumors should be a useful approach for the treatment of tumors. Previous studies have shown that introduction of new antigens into tumor cells stimulates immune responses against autologous malignant cells. In the present study, intratumoral delivery of MV in tumor cells was intended to modify the tumor cells and enhance the presentation ability of the modified tumor cells to antigen-presenting cells (APCs) and then cross-priming through APCs. Our findings found a significant increasing infiltration. However, treatment with MV significantly increased the infiltration of $\mathrm{CD}^{+}$and $\mathrm{CD}^{+} \mathrm{T}$ lymphocytes in the tumor tissues of the MV-treated group coincident with previous reports (Fig. 6). 


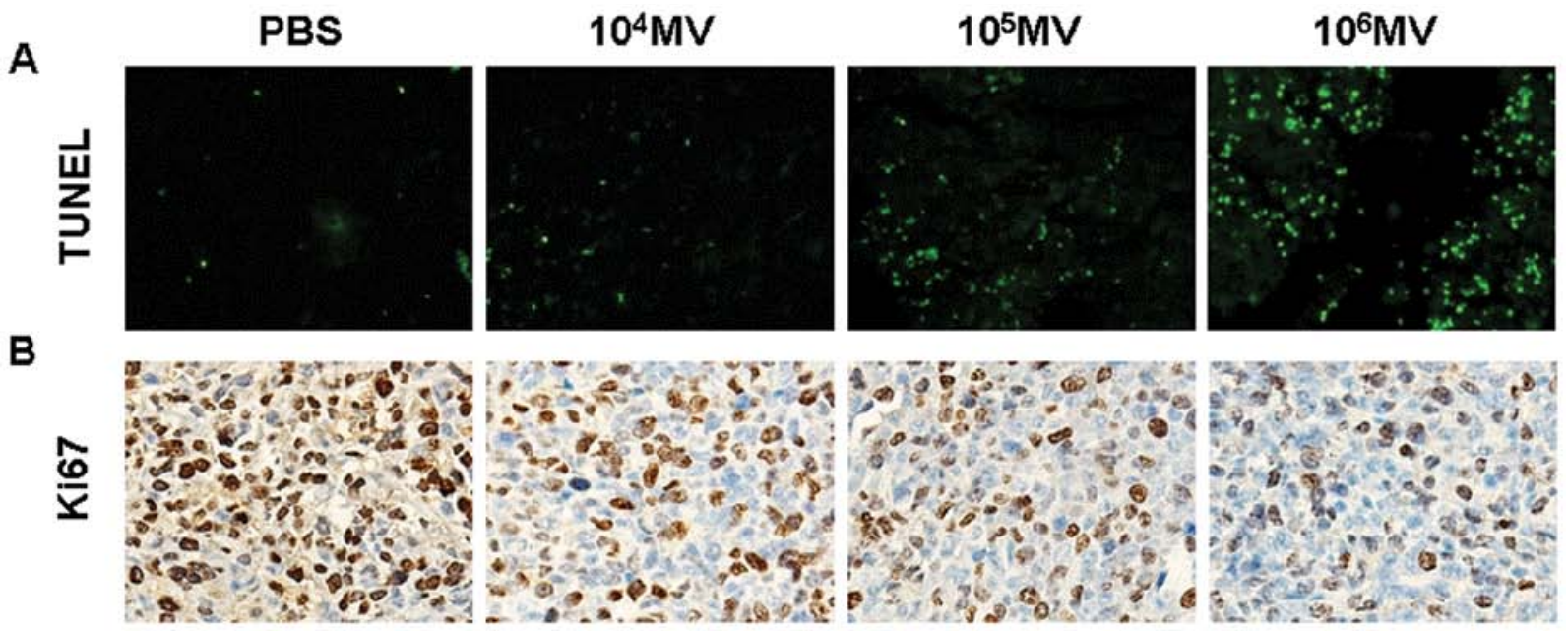

Figure 4. Detection of apoptosis and proliferation in tumor tissues. (A) Apoptotic cells within tumor tissues were evaluated by TUNEL assays. An apparent increase in the number of apoptotic cells was observed within the tumor tissues treated with $10^{6} \mathrm{CCID}_{50} / \mathrm{ml} \mathrm{MV}$ compared with the control groups (B) Immunohistochemical analysis with the anti-Ki67 antibody, used to measure proliferation in tumor tissues, showed less proliferative cells within the tumors treated with $10^{6} \mathrm{CCID}_{50} / \mathrm{ml} \mathrm{MV}$, compared with the other groups.

A
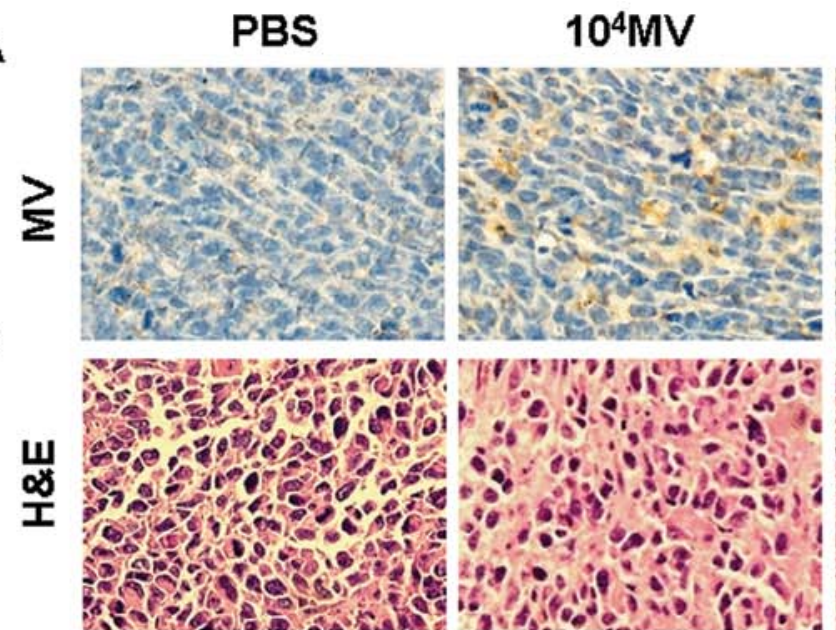

$10^{4} \mathrm{MV}$

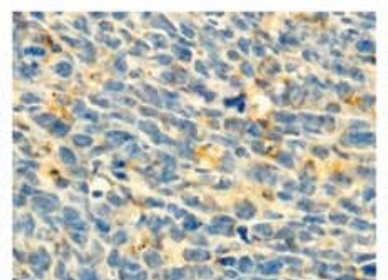

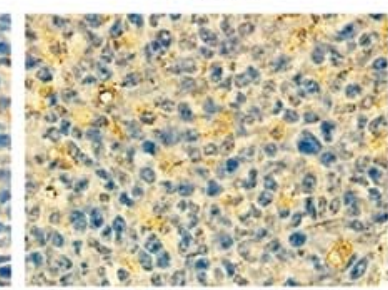

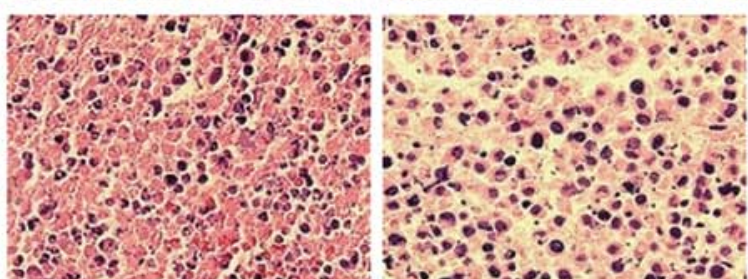

$10^{6} \mathrm{MV}$

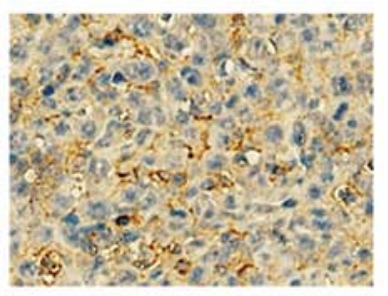

Figure 5. Immunohistochemical analysis of measles virus (MV) and histopathological examination of tumors. (A). More $\mathrm{MV}$ was detected in the $10^{6} \mathrm{CCID} \mathrm{D}_{50} / \mathrm{ml}$ $\mathrm{MV}$-treated group than the other three groups. (B) There were large areas of confluent tumor cells with little or no tumor tissue necrosis $\left(\mathrm{PBS}, 10^{4} \mathrm{CCID} \mathrm{C}_{50} / \mathrm{ml}\right.$

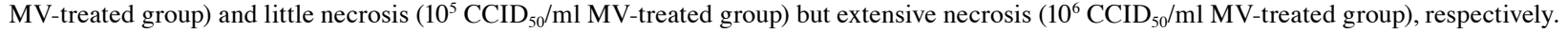

A

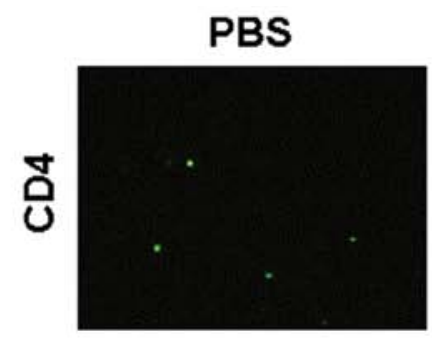

B

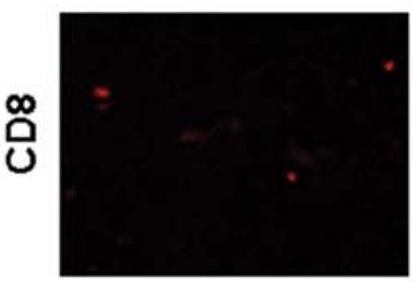

$10^{4} \mathrm{MV}$
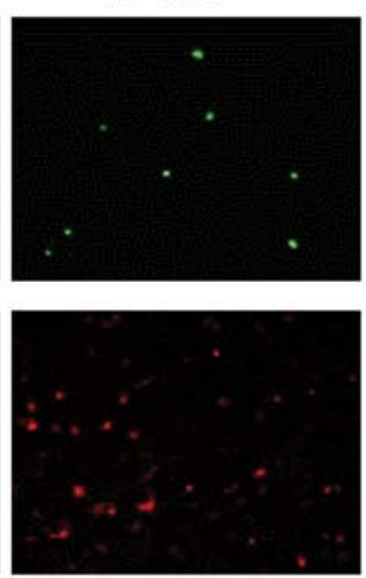

$10^{5} \mathrm{MV}$
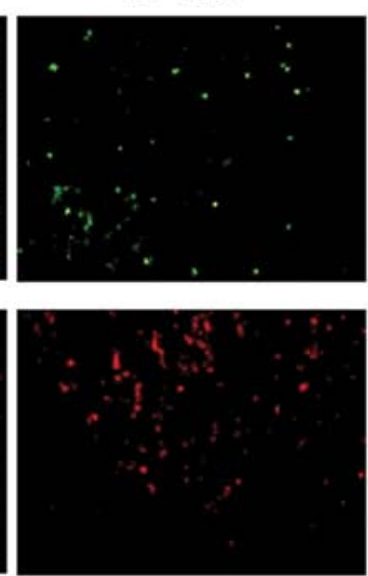
The management of unresectable lung cancers remains a major therapeutic challenge to medical oncologists. Our observations may have potential implications for the treatment of human lung cancer by MV, since MV is capable of repressing tumor growth when administered.

Collectively, the present study showed that MV treatment resulted in statistically significant reduction in tumor growth, increased apoptosis of lung cancer cells in vitro and in vivo, and increased infiltration of lymphocytes, while significantly prolonging the survival of tumor-bearing animals. In addition, there was no obvious undesired toxicity following treatment. Our findings suggest that intratumoral delivery of MV may be a promising strategy for the treatment of lung cancer. Further studies involving this treatment strategy, used alone or in combination with chemotherapy and biotherapy, warrant consideration. Live attenuated measles vaccine may be used as a novel type of anticancer drug.

\section{References}

1. Minna JD, Roth JA and Gazdar AF: Focus on lung cancer. Cancer Cell 1: 49-52, 2002.

2. Jemal A, Siegel R, Ward E, Murray T, Xu J and Thun MJ: Cancer statistics, 2007. CA Cancer J Clin 57: 43-66, 2007.

3. Schiller JH, Harrington D, Belani CP, Langer C, Sandler A, Krook J, Zhu J and Johnson DH; Eastern Cooperative Oncology Group: Comparison of four chemotherapy regimens for advanced non-small-cell lung cancer. N Engl J Med 346: 92-98, 2002.

4. Khuri FR, Herbst RS and Fossella FV: Emerging therapies in non-small-cell lung cancer. Ann Oncol 12: 739-744, 2001.

5. Soria JC, Jang SJ, Khuri FR, Hassan K, Liu D, Hong WK and Mao L: Overexpression of cyclin B1 in early-stage non-small cell lung cancer and its clinical implication. Cancer Res 60: 4000-4004, 2000

6. Vora SA, Daly BD, Blaszkowsky L, McGrath JJ, Bankoff M, Supran S and Dipetrillo TA: High dose radiation therapy and chemotherapy as induction treatment for stage III nonsmall cell lung carcinoma. Cancer 89: 1946-1952, 2000.

7. Peng KW, Facteau S, Wegman T, O'Kane D and Russell SJ: Non-invasive in vivo monitoring of trackable viruses expressing soluble marker peptides. Nat Med 8: 527-531, 2002.

8. Zhong H, Han B, Tourkova IL, Lokshin A, Rosenbloom A, Shurin MR and Shurin GV: Low-dose paclitaxel prior to intratumoral dendritic cell vaccine modulates intratumoral cytokine network and lung cancer growth. Clin Cancer Res 13: 5455-5462, 2007.

9. Erlenhoefer C, Wurzer WJ, Löffler S, Schneider-Schaulies S, ter Meulen V and Schneider-Schaulies J: CD150 (SLAM) is a receptor for measles virus but is not involved in viral contactmediated proliferation inhibition. J Virol 75: 4499-4505, 2001.

10. Tatsuo H, Ono N, Tanaka K and Yanagi Y: SLAM (CDw150) is a cellular receptor for measles virus. Nature 406: 893-897, 2000.

11. Hsu EC, Iorio C, Sarangi F, Khine AA and Richardson CD: CDw150 (SLAM) is a receptor for a lymphotropic strain of measles virus and may account for the immunosuppressive properties of this virus. Virology 279: 9-21, 2001.

12. Dörig RE, Marcil A, Chopra A and Richardson CD: The human CD46 molecule is a receptor for measles virus (Edmonston strain). Cell 75: 295-305, 1993.

13. Naniche D, Varior-Krishnan G, Cervoni F, Wild TF, Rossi B, Rabourdin-Combe C and Gerlier D: Human membrane cofactor protein (CD46) acts as a cellular receptor for measles virus. J Virol 67: 6025-6032, 1993.

14. Bjørge L, Hakulinen J, Wahlström T, Matre R and Meri S: Complement-regulatory proteins in ovarian malignancies. Int $\mathrm{J}$ Cancer 70: 14-25, 1997.
15. Grote D, Russell SJ, Cornu TI, Cattaneo R, Vile R, Poland GA and Fielding AK: Live attenuated measles virus induces regression of human lymphoma xenografts in immunodeficient mice. Blood 97: 3746-3754, 2001.

16. Grote D, Cattaneo R and Fielding AK: Neutrophils contribute to the measles virus-induced antitumor effect: enhancement by granulocyte macrophage colony-stimulating factor expression. Cancer Res 63: 6463-6468, 2003.

17. Peng KW, Ahmann GJ, Pham L, Greipp PR, Cattaneo R and Russell SJ: Systemic therapy of myeloma xenografts by an attenuated measles virus. Blood 98: 2002-2007, 2001.

18. Dingli D, Peng KW, Harvey ME, Greipp PR, O'Connor MK, Cattaneo R, Morris JC and Russell SJ: Image-guided radiovirotherapy for multiple myeloma using a recombinant measles virus expressing the thyroidal sodium iodide symporter. Blood 103: 1641-1646, 2004.

19. Phuong LK, Allen C, Peng KW, Giannini C, Greiner S, TenEyck CJ, Mishra PK, Macura SI, Russell SJ and Galanis EC: Use of a vaccine strain of measles virus genetically engineered to produce carcinoembryonic antigen as a novel therapeutic agent against glioblastoma multiforme. Cancer Res 63: 2462-2469, 2003.

20. Peng KW, TenEyck CJ, Galanis E, Kalli KR, Hartmann LC and Russell SJ: Intraperitoneal therapy of ovarian cancer using an engineered measles virus. Cancer Res 62: 4656-4662, 2002.

21. Pumphrey CY, Theus AM, Li S, Parrish RS and Sanderson RD: Neoglycans, carbodiimide-modified glycosaminoglycans: a new class of anticancer agents that inhibit cancer cell proliferation and induce apoptosis. Cancer Res 62: 3722-3728, 2002.

22. Wei YQ, Zhao X, Kariya Y, Fukata H, Teshigawara K and Uchida A: Induction of apoptosis by quercetin: involvement of heat shock protein. Cancer Res 54: 4952-4957, 1994.

23. Gorczyca W, Gong J, Ardelt B, Traganos F and Darzynkiewicz Z: The cell cycle related differences in susceptibility of HL-60 cells to apoptosis induced by various antitumor agents. Cancer Res 53: 3186-3192, 1993.

24. Barry MA, Reynolds JE and Eastman A: Etoposide-induced apoptosis in human HL-60 cells is associated with intracellular acidification. Cancer Res 53: 2349-2357, 1993.

25. Sauter BV, Martinet O, Zhang WJ, Mandeli J and Woo SL: Adenovirus-mediated gene transfer of endostatin in vivo results in high level of transgene expression and inhibition of tumor growth and metastases. Proc Natl Acad Sci USA 97: 48024807, 2000.

26. Wei YQ, Hang ZB and Liu KF: In situ observation of inflammatory cell-tumor cell interaction in human seminomas (germinomas): light, electron microscopic, and immunohistochemical study. Hum Pathol 23: 421-428, 1992.

27. Li G, Tian L, Hou JM, Ding ZY, He QM, Feng P, Wen YJ, Xiao F, Yao B, Zhang R, Peng F, Jiang Y, Luo F, Zhao X, Zhang L, Zhou Q and Wei YQ: Improved therapeutic effectiveness by combining recombinant $\mathrm{CXC}$ chemokine ligand 10 with cisplatin in solid tumors. Clin Cancer Res 11: 4217-4224, 2005.

28. Xiao F, Wei Y, Yang L, Zhao X, Tian L, Ding Z, Yuan S, Lou Y, Liu F, Wen Y, Li J, Deng H, Kang B, Mao Y, Lei S, He Q, Su J, Lu Y, Niu T, Hou J and Huang MJ: A gene therapy for cancer based on the angiogenesis inhibitor, vasostatin. Gene Ther 9: 1207-1213, 2002

29. Peto R and Peto J: Asymptotically efficient rank invariant test procedures. J R Stat Soc Ser A 135: 185-207, 1972.

30. Malaguarnera L: Implications of apoptosis regulators in tumorigenesis. Cancer Metastasis Rev 23: 367-387, 2004.

31. Liu TC and Kim D: Systemic efficacy with oncolytic virus therapeutics: clinical proof-of-concept and future directions. Cancer Res 67: 429-432, 2007.

32. Parato KA, Senger D, Forsyth PA and Bell JC: Recent progress in the battle between oncolytic viruses and tumours. Nat Rev Cancer 5: 965-976, 2005. 